\title{
Anafilaxia em estudantes acima de sete anos nas escolas públicas de Imperatriz do Maranhão - MA
}

\author{
Anaphylaxis in public school students aged 7 years or older in Imperatriz do Maranhão, MA, Brazil \\ Cayo Fernando de-Araújo-Sousa1, Marcos da Silva Oliveira1, \\ Antonio Francisco e-Silva-Junior ${ }^{1}$, Raphael Coelho Figueredo², Elaine Gagete ${ }^{3}$
}

\section{RESUMO}

Introdução: Anafilaxia é uma reação de hipersensibilidade aguda, grave, potencialmente fatal, causada por mecanismos de hipersensibilidade. A prevalência da anafilaxia está crescendo, entretanto, pesquisas epidemiológicas sobre esta doença ainda são escassas no Brasil, o que motivou o presente estudo. Métodos: A pesquisa é observacional e com delineamento do tipo transversal, baseada na aplicação de questionário validado que sugere o diagnóstico de anafilaxia em crianças e adolescentes entre 7 a 18 anos em escolas públicas da cidade de Imperatriz, Maranhão, Brasil. Simultaneamente, outro questionário correlacionando características socioeconômicas e de saúde geral também foi aplicado. Foram sorteadas 30 escolas, e em cada uma delas foram sorteados 24 estudantes. Os questionários devolvidos foram processados, sendo que escores iguais ou acima de 28 foram identificados como sugestivos de anafilaxia. Dois grupos, sem e com anafilaxia, (respectivamente, A e B) foram comparados. Resultados: Dos 720 questionários entregues, 380 foram devolvidos e, destes, 294 foram considerados válidos e analisados. Destes 294, 144 (49\%) alegaram já ter tido pelo menos uma crise de alergia e tiveram seus questionários tabulados. Dezessete entrevistados $(5,78 \%$ dos 294$)$ apresentaram escores iguais ou superiores a 28, o que sugere anafilaxia. Com relação ao segundo questionário, os grupos A e B apresentaram diferenças estatisticamente significativas quanto ao gênero, renda familiar, presença de tabagismo passivo e vacinação, sendo que o grupo B apresentou, respectivamente, predomínio do gênero feminino, maior renda familiar, maior índice de tabagismo passivo e vacinação completa. Conclusões: As taxas de prevalência de anafilaxia em pessoas suspeitas dessa doença em Imperatriz do Maranhão mostram-se significativas e comparáveis a outros locais já estudados no Brasil e no mundo. Mais estudos epidemiológicos são necessários para se ampliar o conhecimento dessa prevalência no país e sua correlação com dados socioeconômicos e de saúde geral.

Descritores: Anafilaxia, epidemiologia, inquéritos e questionários.

\section{ABSTRACT}

Introduction: Anaphylaxis is a severe, potentially life-threatening hypersensitivity reaction, and its prevalence has been increasing. Despite the importance of this disease, there are few studies focusing on its epidemiological aspects in Brazil. Hence, the authors aimed to investigate the prevalence of anaphylaxis in Imperatriz, a city in Maranhão (MA) - a Northwest state in Brazil - as a contribution to the understanding of this issue. Methods: Thirty public schools were chosen at random, and in each one, 24 students were chosen randomly. A validated questionnaire to collect data on possible anaphylactic reactions was sent to them along with socioeconomic and general health questions. The answers were analyzed to identify who could have had an anaphylactic reaction. A score of 28 or higher indicated a possible anaphylactic reaction. The group with possible anaphylaxis was compared with the group without anaphylaxis. Results: Of 720 questionnaires sent to the students, $320(52.8 \%)$ were returned and 294 were considered for analysis. Of 294, 144 (49\%) students answered that they had had at least one episode of allergic reaction and, thus, had their answers tabulated. Seventeen students scored 28 or higher and were considered to have had an anaphylactic reaction. Therefore, the prevalence of anaphylaxis in this population was $5.78 \%(17 / 294)$. A comparison of the two groups, without anaphylaxis (A) and with possible anaphylaxis (B), showed that group B statistically differed in gender (more female), family income, second-hand smoking, and vaccination rate (higher indices in group $B$ ). Conclusion: Anaphylaxis is an important disease in Imperatriz (MA), and its prevalence is similar to that of other places in Brazil and in the world. More studies are necessary to better understand how anaphylaxis impacts the Brazilian population.

Keywords: Anaphylaxis, epidemiology, surveys and questionnaires.

1. Universidade Federal do Maranhão, Medicina - Imperatriz, MA, Brasil.

2. Universidade Iguaçu, Medicina - Rio de Janeiro, RJ, Brasil.

3. Associação Brasileira de Alergia e Imunologia, Membro do Comitê de Anafilaxia - São Paulo, SP, Brasil.

Submetido em: 24/02/2021, aceito em: 23/05/2021.

Arq Asma Alerg Imunol. 2021;5(3):279-90.

http://dx.doi.org/10.5935/2526-5393.20210044 


\section{Introdução}

Anafilaxia é uma reação de hipersensibilidade generalizada, de início súbito e evolução rápida, potencialmente fatal, que ocorre a partir de mecanismos imunológicos ou não. Tipicamente, dois ou mais órgãos ou sistemas são acometidos. Os órgãos mais envolvidos são pele e mucosas, entretanto, outros sistemas podem ser comprometidos, até mesmo na ausência de sintomas cutaneomucosos, como aparelho respiratório, trato gastrointestinal, sistema cardiovascular e sistema nervoso central ${ }^{1}$.

O diagnóstico da anafilaxia é eminentemente clínico e baseia-se nos critérios recomendados por diretrizes internacionais mostrados na Tabela $1^{2}$. Quando um ou mais critérios estão presentes, o diagnóstico de anafilaxia deve ser cogitado. A validação de tais critérios mostrou que sua sensibilidade é alta $(95 \%)$, mas a especificidade é pouco maior que $80 \%$, ou seja, apesar de muito útil, o diagnóstico pode ser superestimado em quase $20 \%$ dos casos $^{3}$. Assim, apesar de esses critérios serem adequados na emergência, onde o risco de um subdiagnóstico traria consequências muito mais graves ao paciente, eles não substituem avaliação mais rigorosa pelo alergista para um diagnóstico mais preciso 4 .

A verdadeira prevalência de anafilaxia é desconhecida, porém, calcula-se que existam entre 50-2.000 episódios de anafilaxia para cada 100.000 pessoas e, portanto, $2 \%$ aproximadamente da população já teve pelo menos um episódio de anafilaxia ao longo de sua vida, sendo que a etiologia mais importante são drogas, veneno de insetos e alimentos. A importância desses desencadeantes está relacionada principalmente com a faixa etária e com o método utilizado. Por exemplo, alimento é a causa mais provável em crianças, enquanto medicamentos são os desencadeantes mais frequentes em pacientes hospitalizados, especialmente entre os de maior idade. De interesse ressaltar que essas pesquisas apontam não apenas o aumento da incidência e prevalência, mas também da gravidade dessas reações ${ }^{5-12}$.

No Brasil, ainda há poucos estudos sobre anafilaxia. Em 2010, questionário enviado pela Associação Brasileira de Alergia e Imunologia (ASBAI) para seus associados, mostrou que os principais desencadeantes de reações anafiláticas foram os medicamentos $(45,13 \%)$, seguidos por alimentos e insetos $(18,58 \%$ cada) e outros, como látex, atividade física, imunoterapia e causas não conhecidas. Infelizmente, a participação foi pequena, e poucos questionários retornaram nesse estudo ${ }^{13}$.

Uma pesquisa mais robusta envolvendo países da América Latina também mostrou que as medicações foram as mais implicadas nas crises anafiláticas, especialmente os anti-inflamatórios não esteroidais, seguidos por antibióticos; alimentos vêm em segundo lugar, sendo os mais envolvidos: peixe e frutos do mar, leite, frutas, trigo, amendoim, ovo, castanhas, mandioca e outros; alergia a veneno de insetos, imunoterapia, látex, exercícios e contrastes iodados vieram a seguir ${ }^{14}$.

Tabela 1

Critérios clínicos para o diagnósticos de anafilaxia ${ }^{2}$

1 - Início agudo, com envolvimento cutâneo e/ou mucoso, e pelo menos um dos seguintes achados:

a. Comprometimento respiratório (ex. dispneia, broncoespasmo, estridor, hipóxia);

b. Comprometimento cardiocirculatório (ex.: hipotensão, colapso).

2 - Dois ou mais dos seguintes achados após exposição (de minutos a horas) de alérgenos prováveis:
a. Aparecimento de sintomas cutaneomucosos, ex. urticária, eritema e/ou prurido generalizados, angioedema;
b. Surgimento de sintomas cardiovasculares;
c. Sinais de envolvimento do sistema respiratório;
d. Aparecimento de sintomas gastrointestinais persistentes como cólicas, vômitos e diarreia.

3 - Hipotensão após exposição (de minutos a horas) a um alérgeno ao qual sabidamente o paciente em questão apresenta hiper-reatividade, entendendo-se aqui por hipotensão a queda da pressão sistólica a um nível $30 \%$ abaixo de sua linha basal ou $<90 \mathrm{mmHg}$ para adultos. 
Através de questionário validado, Gagete e cols. ${ }^{15}$ encontraram numa cidade do interior de SP, Brasil, a prevalência de 6,2\% de anafilaxia, onde as drogas, especialmente dipirona, também foram as causas mais comuns.

Considerando a escassez de estudos epidemiológicos em nosso país, fica claro o interesse em pesquisas dessa natureza com a finalidade de se mapear o problema nas diversas regiões.

No presente estudo, os autores oferecem uma contribuição ao conhecimento da anafilaxia em Imperatriz do Maranhão, estado do Nordeste do Brasil.

\section{Método}

Imperatriz é um município localizado ao sudoeste do Maranhão, sendo a segunda cidade mais populosa do estado, com 259.337 habitantes, segundo o IBGE, censo de $2020^{16}$.

Foi idealizado um estudo analítico, observacional e com delineamento do tipo transversal, baseado na aplicação de questionário validado para uso em pesquisas epidemiológicas no Brasil em pessoas com 7 anos de idade ou mais ${ }^{15}$, o qual foi aplicado em alunos entre 7 a 18 anos de idade matriculados no ensino fundamental ou médio nas redes de ensino público de Imperatriz, MA. Por razões alheias à vontade dos pesquisadores, as escolas particulares, em sua totalidade, não permitiram que seus alunos fossem abordados.

Tal questionário, cujo detalhamento encontra-se na publicação original, foi desenvolvido através de questões que sugerem ou descartam anafilaxia e sua padronização foi realizada em pacientes que sabidamente apresentavam ou não o diagnóstico. Após várias análises, chegou-se ao modelo final deste instrumento com 10 questões e diversas subquestões, sendo que cada uma delas apresenta um peso positivo ou negativo, de acordo com a maior ou menor probabilidade de se tratar ou não de anafilaxia. Os grupos foram comparados e através de curva ROC chegou-se a um escore de 28 , que é um valor onde especificidade e sensibilidade atingem o melhor ponto, ou seja, questionários que somam 28 pontos ou mais apresentam grande chance de se tratar de anafilaxia (vide Anexo 1). Além desse instrumento padronizado, foi aplicado um outro questionário com questões que pudessem avaliar a população estudada com relação a suas características sociodemográficas e de saúde geral (Anexo 2). Ambos os questionários foram entregues aos alunos com carta explicativa sobre o estudo e solicitando aos pais que preenchessem os mesmos, especialmente no caso de crianças entre 7 e 15 anos.

O tamanho da amostra foi calculado com base no intervalo de confiança de $95 \%$ e erro máximo admissível de $5 \%$ de um universo de 54.088 estudantes de acordo com o censo de 2014 do INEP $^{17}$. Portanto, o tamanho da amostra foi de pelo menos 384 estudantes. Para tal, considerando a taxa aproximada de perda de $85 \%$ (TCLE não autorizado pelos pais, questionários incorretamente preenchidos e não devoluções dos questionários aos pesquisadores), foram abordados 720 escolares. A coleta dos dados foi realizada entre janeiro e abril de 2019. A pesquisa foi aprovada pelo conselho de ética em pesquisa da Fundação Universidade Federal do Maranhão, com o número do parecer de 3.051.937. A autorização para a realização da pesquisa foi fornecida pela Secretaria Municipal de Educação e pelo diretor de cada instituição de ensino. As escolas foram selecionadas de acordo com um plano de amostragem aleatória simples, sendo a cidade dividida em 4 macrorregiões, e em cada região, foram sorteadas em média 7 escolas, a fim de que a pesquisa alcançasse o território municipal homogeneamente. Sendo assim, foram sorteadas 30 escolas municipais de Imperatriz em um universo de 90 escolas listadas pela Secretaria Municipal de Educação.

Dentro de cada uma das 30 escolas, foram realizados sorteios aleatórios de duas turmas e, em cada turma sorteada, houve sorteios de 12 estudantes, contabilizando assim 24 indivíduos por escola e, consequentemente, 720 questionários aplicados. Em cada escola, os examinadores na presença de um representante da coordenação, explicaram sobre o questionário e a importância do estudo, bem como estimularam os escolares a discutir os detalhes de sua história clínica juntamente com os pais ou responsáveis, uma vez que os questionários eram levados para casa pelos alunos.

Após a devolução, os dados da amostra foram organizados em planilha eletrônica no software Microsoft Excel ${ }^{\circledR} 2010$ e através de fórmula do próprio programa foi obtido o escore (soma dos pontos multiplicados por seus respectivos pesos). Para a comparação do grupo sem anafilaxia (aqui chamado de Grupo A) e com anafilaxia (Grupo B) foi aplicado o teste $t$ de Student de diferenças de média através do software Stata. 


\section{Resultados}

Dos 720 questionários entregues, foram devolvidos 380 (52,8\%). Destes, apenas 294 questionários foram considerados válidos e se constituíram no total de instrumentos avaliados ( $n$ total), sendo que os 86 descartados estavam incompletos e/ou ilegíveis. Destes 294 questionários, 49\% $(n=144)$ alegaram possuir pelo menos uma crise de alergia alguma vez na vida, e tiveram suas respostas avaliadas e pontuadas para efeito de escore. Os demais, que responderam nunca terem tido nenhuma crise alérgica, encerravam o questionário neste ponto, mas foram considerados no cálculo geral (vide abaixo). Após análise das respostas pontuadas através dos pesos correspondentes, obteve-se 17 questionários com escore de 28 ou mais (sugestivo de anafilaxia), o que corresponde a 5,78\% em relação aos 294 questionários válidos. $O$ detalhamento dos pacientes com anafilaxia é mostrado nas Tabelas 2 e 3.

Considerando estes 294 questionários, 37,1\% ( $n=109$ ) foram do gênero masculino, e $62,9 \%$ $(n=185)$ do feminino. Quanto à faixa etária, $21,8 \%$ $(n=64)$ foram crianças entre 7 a 12 anos, e $78,2 \%$ $(n=230)$ adolescentes entre 13 a 18 anos.

O grupo dos 144 questionários que responderam apresentar pelo menos um tipo de alergia foi subdividido em Grupo A (escore < 28) e Grupo B (escore acima de 28) e foi feita comparação entre os caracteres sociodemográficos desses grupos. Não foi possível realizar comparação entre o grupo que respondeu que nunca teve qualquer reação alérgica e os demais, pois o número de questionários sociodemográficos respondidos pelos não alérgicos foi ínfimo, prejudicando a análise.

A Tabela 4 apresenta a comparação supra citada. Foram encontradas diferenças significativas quanto ao gênero, renda familiar, presença de tabagismo passivo e vacinação, onde o grupo $B$ apresentou, respectivamente, predomínio do gênero feminino, maior renda familiar, maior índice de tabagismo passivo e vacinação completa.

\section{Discussão}

A anafilaxia é uma emergência médica e seus portadores devem ser identificados e orientados para se evitar um desfecho desfavorável em crises posteriores. Apesar de inquestionável o uso precoce de adrenalina e a orientação para o reconhecimento imediato dos sintomas, ainda há subdiagnóstico e subtratamento tanto no Brasil como em outros países. Pesquisas para se estudar a prevalência ou incidência provêm de casuísticas diversas, difíceis de se comparar, como internações, base de dados de serviços públicos ou privados, dispensação de adrenalina, etc. ${ }^{18}$.

Aqui no Brasil são raras as pesquisas epidemiológicas para se entender melhor o comportamento da anafilaxia em nosso meio ${ }^{13,15}$, e até onde os autores têm conhecimento este é o primeiro trabalho epidemiológico focando uma faixa populacional de uma cidade maranhense.

A utilização de questionários para pesquisas epidemiológicas conta com vários desafios, especialmente no que concerne ao nível de entendimento de quem está sendo entrevistado. Infelizmente, nossa população é pouco escolarizada e pode-se imaginar que há muitos analfabetos funcionais cuja capacidade de compreensão do texto é limitada. No atual estudo optou-se por realizar a pesquisa entre estudantes para minimizar tal problema, embora a pesquisa tenha incluído a faixa etária pediátrica, cujo questionário deveria ter sido preenchido pela família. É provável que a incapacidade funcional de se entender o que se pede através de um instrumento escrito explique o retorno de apenas $52,8 \%$ dos questionários e, do total devolvido, apenas $49 \%$ possam ter sido utilizados, pois os demais apresentavam graves problemas de inconsistência ou falta de preenchimento adequado e foram descartados. Note-se que $78,2 \%$ dos questionários foram preenchidos pelo próprio entrevistado(a), no caso, adolescentes, que provavelmente tiveram mais domínio sobre o instrumento em relação aos pais de crianças menores. Há que se pontuar, contudo, que mesmo entre estudantes, especialmente do ensino público no Brasil, o analfabetismo funcional ainda tem que ser considerado, o que torna um desafio pesquisas epidemiológicas utilizando questionários autoaplicados. Esta é uma limitação deste trabalho.

Apesar dos óbices na utilização de questionários populacionais, eles têm se mostrado úteis em várias áreas da Medicina e na Alergologia o estudo ISAAC é o mais conhecido ${ }^{19,20}$. Nas pesquisas epidemiológicas com foco em anafilaxia, tais instrumentos também já foram utilizados. Na Austrália um entrevistador inquiria os pais por telefone utilizando questionário não padronizado, e o índice de anafilaxia foi de 0,59\%. Os autores também encontraram dois terços dessas crianças sem uso de medicação de urgência no ambiente escolar ${ }^{21}$. Pesquisas populacionais utilizandose entrevistador podem ser úteis, entretanto, colocam 


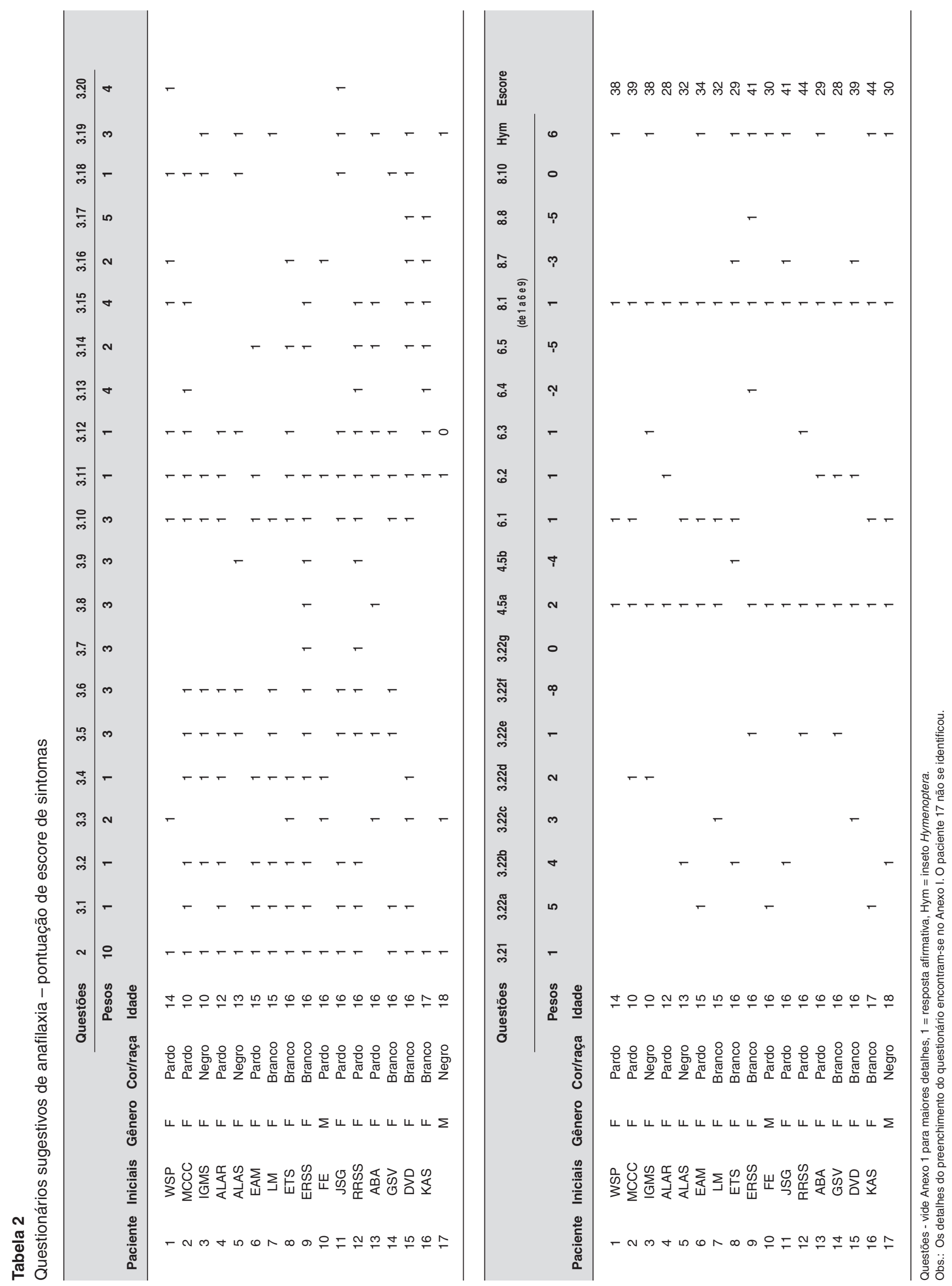




\section{Tabela 3}

Questionários sugestivos de anafilaxia - questões descritivas

\begin{tabular}{|c|c|c|c|c|c|c|c|}
\hline Número & Gênero & Idade & Escore & Causa provável & $\begin{array}{l}\text { Número de } \\
\text { episódios }\end{array}$ & $\begin{array}{l}\text { Confirmação por } \\
\text { teste ou exame }\end{array}$ & $\begin{array}{c}\text { Tempo entre } \\
\text { desencadeamento } \\
\text { e reação }\end{array}$ \\
\hline 1 & $\mathrm{~F}$ & 14 & 38 & Ferroada de abelha & 4 ou mais & Nega & Não relatado \\
\hline 2 & $\mathrm{~F}$ & 10 & 39 & Não identificado & 2 & Nega & Desconhece \\
\hline 3 & $\mathrm{~F}$ & 10 & 38 & Ferroada de formiga & 2 & Nega & 2 horas \\
\hline 4 & $\mathrm{~F}$ & 12 & 28 & Dipirona & 4 ou mais & Nega & Entre 5-30 minutos \\
\hline 5 & $\mathrm{~F}$ & 13 & 32 & Banana & 1 & Não respondido & Entre 5-30 minutos \\
\hline 6 & $\mathrm{~F}$ & 15 & 34 & Ferroada de formiga & 1 & Não respondido & Entre 5-30 minutos \\
\hline 7 & $\mathrm{~F}$ & 15 & 32 & Dipirona & 4 ou mais & Nega & Entre 1 e 2 horas \\
\hline 8 & $\mathrm{~F}$ & 16 & 29 & Ferroada de inseto & 3 & Nega & Entre 30 e 60 minutos \\
\hline 9 & $\mathrm{~F}$ & 16 & 41 & Dipirona e ferroada de insetos & 4 ou mais & Sim & Acima de 2 horas \\
\hline 10 & M & 16 & 30 & Dipirona e ferroada de insetos & 2 & Nega & Não lembra \\
\hline 11 & $\mathrm{~F}$ & 16 & 41 & Abelha, leite e camarão & 4 ou mais & Sim & Entre 5-30 minutos \\
\hline 12 & $\mathrm{~F}$ & 16 & 44 & Ferroada de inseto & 2 & Sim & Não lembra \\
\hline 13 & $\mathrm{~F}$ & 16 & 29 & Ferroada de abelha & 1 & Sim & Entre 30 e 60 minutos \\
\hline 14 & $\mathrm{~F}$ & 16 & 28 & Dipirona & 3 & Nega & Entre 1 e 2 horas \\
\hline 15 & $\mathrm{~F}$ & 16 & 39 & Látex & 4 ou mais & Nega & Entre 1 e 2 horas \\
\hline 16 & $\mathrm{~F}$ & 17 & 44 & Dipirona e ferroada de formiga & 3 & Sim & Menos de 5 minutos \\
\hline 17 & M & 18 & 30 & Ferroada de marimbondo & 4 ou mais & Não respondido & Entre 5-30 minutos \\
\hline
\end{tabular}

mais uma variável que é a condução das respostas pela própria pessoa que aplica o questionário. Para se superar este problema, o instrumento deve ser apenas lido para o respondedor.

O presente estudo chegou a uma prevalência de $5,78 \%$, que é semelhante ao que Gagete e cols. chegaram em Botucatu, SP $(6,2 \%)^{15}$, e fica na média comparativamente a outros estudos sumarizados por Tejedor-Alonso e cols. ${ }^{22}$.

Chama a atenção, observando-se o grupo B referente aos pacientes portadores de anafilaxia, que a grande maioria referiu inseto (abelha, vespa ou formiga) como desencadeante. Isso pode ser explicado pelo fato de Imperatriz ser uma cidade do interior do Maranhão, onde a zona rural é próxima à urbana e há grande exposição das pessoas nessas áreas onde existe mais insetos himenópteros. Também se nota que os entrevistados $9,10,11$ e 16 do grupo $B$ referiram mais de um desencadeante, além das ferroadas de inseto. Pode ser que não tenham entendido no enunciado da questão que poderia ser descrito mais de um desencadeante desde que relacionado à pior crise de alergia descrita no item 3 do questionário. Esse fato pode ter contribuído para o aumento do número de insetos como desencadeantes, já que é difícil saber se a reação anafilática mais grave não se deveu aos outros descritos, como dipirona (entrevistados 9, 10 e 16) e alimentos (camarão e leite, entrevistado 11). Como é pouco provável que todos esses desencadeantes tenham sido de fato os causadores de uma única crise, o mais provável é que os entrevistados tenham misturado vários suspeitos. Além disso, é algo notório que apenas cinco dos 17 respondedores do grupo B tenham procurado médico especialista para orientação e tratamento, mesmo após a referência de várias crises.

Com relação ao questionário sociodemográfico, os autores tentaram obter algum outro dado além da prevalência, alguma correlação com portadores de anafilaxia e fatores que sugerissem aspectos 
relacionados com a hipótese da higiene ${ }^{23}$. Apesar de ter havido diferença significativa com relação ao gênero, renda, vacinação e tabagismo, a casuística é pequena e não é possível chegar-se a uma conclusão mais segura.

A limitação de pesquisas como esta onde se utiliza um questionário é, como já comentado, a dificuldade na compreensão do enunciado por parte dos respondedores. Além disso, o questionário utilizado neste estudo, apesar de validado, deve ser aferido em pesquisas posteriores convocandose os entrevistados com possível diagnóstico de anafilaxia para confirmação, o que não foi feito no presente trabalho por fugir do escopo do estudo. Há que se considerar que o próprio critério diagnóstico para anafilaxia proposto por Sampson e cols. ${ }^{2}$ teve especificidade de aproximadamente $80 \%^{3}$, ou seja, todos os questionários feitos a partir desses critérios

Tabela 4

Diferenças entre os grupos A e B

\begin{tabular}{|c|c|c|c|c|}
\hline & \multicolumn{4}{|c|}{ Diferenças de média entre o Grupo A $(n=127)$ e o Grupo $B(n=17)$} \\
\hline & Média Grupo A & Média Grupo B & Diferença & Erro padrão \\
\hline Gênero = feminino & 0,66 & 0,88 & $-0,221^{a}$ & 0,119 \\
\hline Raça/cor = branco & 0,32 & 0,35 & $-0,030$ & 0,122 \\
\hline Raça/cor = pardo & 0,53 & 0,47 & 0,057 & 0,130 \\
\hline Raça/cor = negro & 0,13 & 0,18 & $-0,043$ & 0,090 \\
\hline Idade & 14,56 & 14,82 & $-0,264$ & 0,714 \\
\hline Pessoas na casa: menos de 3 & 0,24 & 0,29 & $-0,050$ & 0,113 \\
\hline Pessoas na casa: 4 a 5 & 0,55 & 0,53 & 0,022 & 0,162 \\
\hline Pessoas na casa: 6 ou mais & 0,17 & 0,18 & $-0,011$ & 0,097 \\
\hline Água & 0,94 & 1,00 & $-0,055$ & 0,056 \\
\hline Luz & 0,93 & 1,00 & $-0,071$ & 0,063 \\
\hline Renda: até 1 salário-mínimo & 0,24 & 0,24 & 0,001 & 0,110 \\
\hline Renda: até 1-3 salários-mínimos & 0,39 & 0,41 & $-0,018$ & 0,127 \\
\hline Renda: mais de 3 salários-mínimos & 0,03 & 0,18 & $-0,145^{b}$ & 0,055 \\
\hline Renda: não informa & 0,26 & 0,18 & 0,083 & 0,112 \\
\hline Animais: dentro & 0,39 & 0,47 & $-0,077$ & 0,127 \\
\hline Animais: fora & 0,20 & 0,18 & 0,020 & 0,103 \\
\hline Animais: não informa & 0,07 & 0,00 & 0,071 & 0,063 \\
\hline Fumo ativo & 0,02 & 0,00 & 0,016 & 0,030 \\
\hline Fumo passivo & 0,11 & 0,29 & $-0,184^{c}$ & 0,087 \\
\hline Pré-natal: mãe fumou & 0,06 & 0,06 & 0,004 & 0,063 \\
\hline Pré-natal: teve pré-natal & 0,76 & 0,94 & $-0,177^{a}$ & 0,106 \\
\hline Pré-natal: teve problemas & 0,06 & 0,06 & $-0,004$ & 0,060 \\
\hline Parto normal & 0,54 & 0,53 & 0,014 & 0,130 \\
\hline Parto cesárea & 0,35 & 0,41 & $-0,065$ & 0,124 \\
\hline Amamentação até 6 meses & 0,62 & 0,53 & 0,093 & 0,127 \\
\hline Vacinação completa & 0,76 & 1,00 & $-0,236^{c}$ & 0,104 \\
\hline Vacinação incompleta & 0,11 & 0,00 & 0,110 & 0,076 \\
\hline Doenças associadas & 0,09 & 0,00 & 0,087 & 0,069 \\
\hline Outros membros alérgicos & 0,45 & 0,65 & $-0,198$ & 0,129 \\
\hline
\end{tabular}

${ }^{\text {a }} \mathrm{p}$-valor $\leq 0,1 ;{ }^{\mathrm{b}} \mathrm{p}$-valor $\leq 0,01 ;{ }^{\mathrm{c}} \mathrm{p}$-valor $\leq 0,05$.

$\mathrm{SM}=$ salário mínimo. 
serão mais sensíveis que específicos, o que poderia ocasionar uma taxa de diagnóstico acima da real.

Apesar disso, estudos populacionais sobre epidemiologia da anafilaxia são imprescindíveis para dar-se visibilidade a pacientes portadores dessa doença no Brasil, especialmente considerando as dificuldades de se avaliar sua prevalência através de outras formas, devido às peculiaridades inerentes a um sistema de saúde misto (público e privado) e com várias falhas de registro.
Concluindo-se, as taxas de anafilaxia entre estudantes acima de sete anos da rede pública de Imperatriz do Maranhão são similares a outras partes do país e do mundo. Novas pesquisas epidemiológicas são de grande importância para se elucidar o real impacto que a anafilaxia tem sobre a população brasileira. É provável que seja em virtude da falta de dados nacionais que o país não conte ainda com a principal medicação para tratamento da anafilaxia, a adrenalina autoinjetável.

Anexo 1 - Questionário padronizado

\section{IDENTIFICAÇÃO DO(A) ENTREVISTADO(A) SE CRIANÇA OU ADOLESCENTE ENTRE 7 E 16 ANOS, FAVOR SER RESPONDIDO POR UM ADULTO}

Nome e sobrenome (apenas as letras iniciais):

Data nascimento: __________________ Idade:

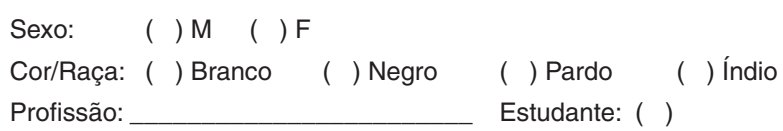

\section{Questão}

1. $\mathrm{O}(\mathrm{a})$ entrevistado(a) já teve pelo menos uma crise de alergia alguma vez na vida?

(Por exemplo: alergia por poeira, por comida, por remédios, asma ou bronquite, alergia na pele, alergia no nariz, etc.)

Não/não sei ( ) Fim da entrevista. Sim ( ) Por favor, responda as próximas questões.

Comentário: Essa questão define quem responderá ou não o questionário.

2. Qual foi o diagnóstico (nome da doença) que o(a) médico(a) deu para a crise de alergia do(a) entrevistado(a)?

(Pode escolher mais de uma opção)

2.1) Asma ou bronquite ( )

2.2) Rinite (alergia no nariz) ou sinusite ou alergia a poeira ( )

2.3) Dermatite ou Eczema ( )

2.4) Urticária ( )

2.5) Edema de glote, fechamento da garganta por alergia, choque anafilático, urticária gigante ou anafilaxia ( )

2.6) Alergia alimentar (alergia a leite, APLV, alergia a ovo, alergia a camarão, alergia por qualquer outro alimento) ( )

2.7) Alergia por medicamentos (remédios), como antibióticos, analgésicos, anestésicos, etc. ( )

2.8) Alergia a insetos, como abelha, vespa, formiga, etc. ( )

2.9) Outro ( ) Qual?

2.10) Não sei ou nunca consultei médico para isso ( )

Comentário: Essa questão valoriza o diagnóstico médico e considera-se que pode ser anafilaxia os subitens de 4 a 8 e o 9 , dependendo da resposta.

Continuação:

Se você marcou os itens de 2.4 a 2.8 pedimos que responda as próximas questões baseado(a) nesses problemas.

Ou seja, mesmo que você tenha marcado também alguma outra alternativa, pedimos que nos aponte a seguir quais os sintomas da pior crise de urticária ou inchaço alérgico ou edema de glote (fechamento da garganta alérgico) ou crise anafilática, ou alergia alimentar ou alergia por remédios ou alergia por insetos que o(a) entrevistado(a) já teve.

- Se você NÃO marcou os itens de 2.4 a 2.8 responda baseado(a) na pior crise que o(a) entrevistado(a) já teve das outras doenças alérgicas marcadas. 


\section{Anexo 1 - Questionário padronizado (continuação)}

3. Entre os sintomas da lista abaixo, quais os que ocorreram durante a pior crise de alergia? Não junte os sintomas de várias crises! Por exemplo, a pessoa pode ter tido num dia uma crise de falta de ar e noutro dia uma crise de vermelhão. Lembre-se da pior crise de alergia que o(a) entrevistado(a) já teve e fale somente sobre ela.

Anote SIM, NÃO ou NÃO SABE/NÃO LEMBRA.

Para "QUAIS" escreva sua resposta.

Durante a pior crise alérgica o(a) entrevistado(a) apresentou:

3.1) Vermelhão no rosto e pescoço $\operatorname{SIM}($ ) NÃO ( ) Não sabe/não lembra ( )

3.2) Vermelhão em outras partes do corpo SIM ( ) Quais?

3.3) Coceira no couro cabeludo $\operatorname{SIM}($ ) NÃO ( ) Não sabe/não lembra ( )

3.4) Coceira em outras partes do corpo $\operatorname{SIM}($ ) Quais?

3.5 Inchaço nos olhos SIM ( ) NÃO ( ) Não sabe/não lembra ( )

3.6) Inchaço nos lábios SIM ( ) NÃO ( ) Não sabe/não lembra ( )

3.7) Inchaço de língua SIM ( ) NÃO ( ) Não sabe/não lembra ( )

3.8) Inchaço nos genitais (partes íntimas) SIM ( ) NÃO ( ) Não sabe/não lembra ( )

3.9) Inchaço em outras partes do corpo SIM ( ) Quais?

3.10) Urticária (manchas vermelhas e salientes na pele, como grandes picadas de inseto, que coçam muito) NÃO ( ) Não sabe/não lembra ( ) $\operatorname{SIM}($ ) NÃO ( ) Não sabe/não lembra ( )

3.11) Dificuldade para respirar, e/ou tosse, e/ou chiado no peito $\operatorname{SIM}($ ) NÃO ( ) Não sabe/não lembra( )

3.12) Palidez (pessoa ficou "branca", sem cor) SIM ( ) NÃO ( ) Não sabe/não lembra ( )

3.13) Arroxeamento de extremidades (unhas, lábios, orelhas) $\operatorname{SIM}($ ) NÃO ( ) Não sabe/não lembra ( )

3.14) Dificuldade para falar e/ou alteração de voz ou choro, como voz rouca ou choro rouco ou voz fraca ou choro fraco $\operatorname{SIM}($ ) NÃO ( ) Não sabe/não lembra ( )

3.15) Dificuldade para engolir SIM( ) NÃO ( ) Não sabe/não lembra ( )

3.16) Dificuldade para pensar (ou "cabeça estranha", "vista escura", "sensação de sumir os sentidos") SIM( ) NÃO ( ) Não sabe/não lembra ( )

3.17) Perda de consciência ou desmaio SIM ( ) NÃO ( ) Não sabe/não lembra ( )

3.18) Cólicas ou dor de barriga $\operatorname{SIM}($ ) NÃO ( ) Não sabe/não lembra ( )

3.19) Vômitos SIM( ) NÃO( ) Não sabe/não lembra ( )

3.20) Perda de urina ou fezes sem querer SIM ( ) NÃO ( ) Não sabe/nãolembra ( )

3.21) Outros sintomas SIM( ) Quais?_NÃO ( ) Não sabe/não lembra ( )

3.22) Quanto tempo levou do início dos sintomas até a piora total, ou seja, até a crise completa, com todos os sintomas acima? menos de 5 minutos

entre 5 e 30 minutos

entre 30 minutos e 2 horas

entre 2 e 8 hors

entre 8 e 24 horas

acima de 24 horas

não sabe/não lembra

As próximas questões referem-se a tratamento e evolução

Quando há indicação que tratamento e evolução foram compatíveis com anafilaxia.

(Exemplo: paciente teve que ser atendido em pronto atendimento, recebeu medicação parenteral, ficou em observação).

Quando há indicação que o tratamento e evolução não são compatíveis com anafilaxia

(Consideramos nesse caso todos que receberam medicação apenas em casa, ou não lembram de ter ido ao pronto atendimento).

Quando há dúvidas se o tratamento e evolução são compatíveis com anafilaxia (por exemplo, pessoa vai ao pronto atendimento e recebe apenas inalação ou medicação oral ou não lembra o que ocorreu no hospital).

4. O que aconteceu em seguida? (Marcar apenas uma opção considerando a pior crise de alergia que você descreveu na questão número 3 )

4.1) A crise passou sozinha, sem necessidade de medicação. ( ) Se você marcou esse item, vá direto para a questão 6.

4.2) Foi usado remédio na hora que a crise ocorreu e ela passou sem necessidade de procurar ajuda médica ( ) Qual (quais) remédio(s) foi (foram) usado(s)?

Se você marcou esse item, vá direto para a questão 6 .

4.3) Entrevistado(a) teve que receber atendimento de urgência, em Pronto-Socorro ou Clínica ou Centro de Saúde ou Ambulatório Médico ou Hospital ( )

Qual(quais) medicamento(s) foi(foram) usado(s)?

Via oral/pela boca ( ) Intramuscular/no músculo ( ) Endovenoso/na veia ( ) Inalação ( ) Subcutâneo ( )

Não sabe/não lembra ( ) 


\section{Anexo 1 - Questionário padronizado (continuação)}

5. E depois o que ocorreu? (Marcar apenas uma opção considerando a pior crise de alergia que você descreveu na questão número 3)

5.1) Entrevistado(a) melhorou depois do atendimento inicial e teve alta da Emergência.

5.2) Entrevistado(a) teve que ficar em observação por mais de 24 horas ou foi internado(a) ( )

5.2) Entrevistado(a) teve que ir para a UTI (Unidade de Terapia Intensiva) ( )

5.3) Outro ( ) O que?

5.4) Não sabe/não lembra ( )

6. Em quanto tempo o(a) entrevistado(a) voltou ao normal após a crise mais grave?

(Marcar apenas uma opção considerando a pior crise de alergia que você descreveu na questão número 3)

Menos de 12 horas

Entre 12 e 24 horas

Entre 24 e 72 horas

Entre 3 e 7 dias

Mais de 1 semana

Não sabe, não lembra

7. Quantas reações alérgicas já aconteceram (incluindo essa mais grave e as outras semelhantes a essa)? (Marcar apenas uma opção) 1( ) 2( ) 3( ) 4 ou mais ( )

Essa questão é apenas descritiva e não é computada no escore.

8. O que desencadeou a pior crise de alergia do(a) entrevistado(a)? (Pode marcar mais de 1 item mas só se tiver relação com a pior crise de alergia que você descreveu na questão número 3)

8.1) Alimento ( ) Qual(quais)?

8.2) Medicamento ( ) Qual (quais)?

8.3) Ferroada de inseto ( ) Que inseto?

8.4) Látex /borracha (por exemplo: luvas, bicos de chupeta e mamadeira, balões de festa, etc.) ( )

8.5) Exercício físico ( )

8.6) Cirurgia ou procedimento médico, no dentista ou clínica para exames ( ) Que tipo de cirurgia ou procedimento?

8.7) Poeira, ácaros, mofo, pelo de animais, pólen de plantas e/ou mudança do clima ( )

8.8) Emocional ( )

8.9) Outro ( ) Qual (quais)?

8.10) Não sabe/não lembra ( )

$\left({ }^{*}\right)$

Nessa questão cada desencadeante assinalado com $\left({ }^{*}\right)$ valem 1 ponto de forma não cumulativa, ou seja, se a pessoa refere que o desencadeante foi alimento MAIS atividade física ela ganhará 1 ponto apenas.

$\left({ }^{* *}\right)$

Em razão de as anafilaxias mais graves durante a elaboração do questionário terem sido as causadas por insetos himenópteros e por justamente serem elas sintomáticas (por exemplo, de acordo com os autores, casos de parada cardiorrespiratória, ou convulsão, sem nenhum outros sintoma, o que reduziria o escore causando um falso-negativo), esse desencadeante recebe pontuação diferenciada.

As demais questões a partir desse ponto são apenas descritivas e não entram no escore.

Se você marcou a opção 8.10 - final do questionário. Se marcou as opções de 8.1 a 8.9, responda:

9. Esse(s) desencadeante(s) (o que provocou a pior crise de alergia) foi (foram) confirmado(s) por médico(a) através de exames e/ ou testes alérgicos? (Marcar apenas uma opção considerando a pior crise de alergia que você descreveu na questão número 3 ) SIM ( ) NÃO ( ) Não sabe/não lembra ( )

10. Quanto tempo após a exposição a esse(s) desencadeante(s) a crise alérgica começou?

(Marcar apenas uma opção considerando a pior crise de alergia que você descreveu na questão número 3)

Menos de 5 minutos ( )

Entre 5 e 30 minutos ( )

Entre 30 e 60 minutos ( )

Entre 1 e 2 horas ( )

Acima de 2 horas ( ). Quanto tempo?

Não sabe/não lembra 


\section{Atenção: esses dados são sigilosos. Por favor, responda e coloque junto com o outro questionário do(a) entrevistado(a). Obrigado!}

1. Quantas pessoas moram na residência, incluindo o(a) entrevistado(a) e todos os agregados (avós, tios, empregada, etc). Qual a idade das pessoas?

2. A casa onde o(a) entrevistado(a) reside tem os seguintes itens:

( ) água encanada

( ) energia elétrica

( ) número de quartos:

( ) número de banheiros:

3. Renda familiar aproximada:

4. Tem animais no domicílio?

( ) Sim, mas apenas fora de casa

( ) Sim, eles entram em casa, mas não no quarto

( ) Sim, e eles habitam o quarto do(a) entrevistado(a)

Que animais são e quantos são?

( ) Não temos animais

5. Tem fumante na casa? ( ) Não ( ) Sim. Quantos? eles fumam dentro da casa? ( )

O entrevistado(a) é fumante. Fuma cigarros/dia há anos.

6. Mãe fumou durante a gravidez? Se sim, quantos cigarros/dia?

7. Mãe do entrevistado(a) fez pré-natal? ( ) Não ( ) Sim.

Teve algum problema diagnosticado pelo obstetra que fez o pré-natal? ( ) Não ( ) Sim.

Qual?

8. Como o entrevistado(a) nasceu?

( ) parto normal ( ) cesárea. Indicação:

( ) Nasceu no tempo certo ( ) Foi prematuro. De quanto tempo?

Teve algum problema nos primeiros 30 dias de vida?

9. Foi amamentado(a) com leite materno exclusivo (sem outros tipos de leite)? Quanto tempo?

10. $O(a)$ entrevistado(a) recebeu todas as vacinas?

( ) Sim, somente as do Posto de Saúde

( ) Sim, as que são dadas no Posto e também outras de clínicas particulares

( ) A carteira de vacinação está incompleta

( ) Nunca recebeu vacinação

11. Com que idade o(a) entrevistado foi para escolinha ou berçário?

12. Quantas vezes o(a) entrevistado(a) já usou antibiótico na vida (aproximadamente)?

13. Já teve alguma infecção grave (que precisou internação)? ( ) Não
( ) Sim. Qual?
Com que idade?

14. O(a) entrevistado(a) é portador(a) de alguma doença? ( ) Não ( ) Sim. Qual?

Faz algum tratamento médico? ( ) Não ( ) Sim

Se sim, quais medicamentos utiliza de forma contínua (diariamente)?

15. Outros membros próximos da família são portadores de doenças alérgicas (asma, bronquite, rinite ou qualquer outra alergia)? Por favor, descreva para cada um.

Avós maternos:

Avós paternos:

Mãe:

Pai:

Irmão(s): 


\section{Referências}

1. Lieberman P, Kemp SF, Oppenheimer J, Lang DM, Bernstein $L$, Nicklas RA. The diagnosis and management of anaphylaxis: An updated practice parameter. J Allergy Clin Immunol. 2005; 115:483-524.

2. Sampson HA, Munoz-Furlong $A$, Campbell RL, Adkinson Jr NF, Bock SA, Branum A, et al. Second Symposium on the Definition and Management of Anaphylaxis: Summary Report - Second National Institute of Allergy and Infectious Disease/Food Allergy and Anaphylaxis Network Symposium. Ann Emerg Med. 2006;47:373-80.

3. Campbell RL, Hagan JB, Manivannan V, Decker WW, Kanthala AR, Bellolio MF, et al. Evaluation of national institute of allergy and infectious diseases/food allergy and anaphylaxis network criteria for the diagnosis of anaphylaxis in emergency department patients. J Allergy Clin Immunol. 2012;129(3):748-52.

4. Samant SA, Campbell RL, Li JT. Anaphylaxis: diagnostic criteria and epidemiology. Allergy Asthma Proc. 2013;34(2):115-9.

5. Simons FE. Anaphylaxis. J Allergy Clin Immunol. 2010;125(2 Suppl 2):S161-81.

6. Liew WK, Williamson E, Tang MLK. Anaphylaxis fatalities and admissions in Australia. J Allergy Clin Immunol. 2009;123:434-42.

7. Pumphrey RS, Gowland MH. Further fatal allergic reactions to food in the United Kingdom, 1999-2006. J Allergy Clin Immunol. 2007;119:1018-9.

8. Moneret-Vautrin DA, Morisset M, Flabbee J, Beaudouin E, Kanny G. Epidemiology of life-threatening and lethal anaphylaxis: a review. Allergy. 2005;60(4):443-51.

9. LiewWK, WilliamsonE,TangML.Anaphylaxisfatalitiesandadmissions in Australia. J Allergy Clin Immunol. 2009;123(2):434-42.

10. Hoffer V, Scheuerman O, Marcus N, Levy Y, Segal N, Lagovsky I, et al. Anaphylaxis in Israel: experience with 92 hospitalized children. Pediatr Allergy Immunol. 2011;22(2):172-7.

11. Decker WW, Campbell RL, Manivannan V, Luke A, Sauver St. $\mathrm{JL}$, Weaver A, et al. The etiology and incidence of anaphylaxis in Rochester, Minnesota: A report from the Rochester Epidemiology Project. J Allergy Clin Immunol. 2008;122:1161-5.

12. Lin RY, Anderson AS, Shah SN, Nurruzzaman F. Increasing anaphylaxis hospitalizations in the first 2 decades of life: New York State, 1990-2006. Ann Allergy Asthma Immunol. 2008;101:387-93.

13. Bernd LAG, Fleig F, Alves MB, Bertozzo R, Coelho M, Correia J, et al. Anafilaxia no Brasil: Levantamento da ASBAI. Rev bras alerg imunopatol. 2010;33:190-8.
14. Sole D, Ivancevich JC, Borges MS, Coelho MA, Rosario NA, Ardusso LR, Bernd LA; Latin American Anaphylaxis Working Group. Anaphylaxis in Latin America: a report of the online Latin American survey on anaphylaxis (OLASA). Clinics (Sao Paulo). 2011;66(6):943-7.

15. Gagete E, dos Santos LD, de Pontes LG, Castro FM. Who has anaphylaxis in Brazil? Validation of a questionnaire for population studies. World Allergy Organ J. 2017;10(1):40.

16. Brasil, Instituto Brasileiro de Geografia e Estatística, IBGE [Internet]. Disponível em: https://www.ibge.gov.br/cidades-e-estados/ma/ imperatriz.html. Acessado em: 04/02/2021.

17. Brasil, Ministério da Educação[site da internet].Disponívelem:https:// www.gov.br/inep/pt-br/areas-de-atuacao/pesquisas-estatisticas-eindicadores/censo-escolar. Acessado em: 04/02/2021.

18. Silva EGM, Castro FF. Epidemiologia da anafilaxia. Braz J Allergy Immunol. 2014;2(1):21-7.

19. Asher MI, Keil U, Anderson HR, Beasley R, Crane J, Martinez F, et al. International Study of Asthma and Allergies in Childhood (ISAAC): rationale and methods. Eur Respir J. 1995;8:483-91.

20. Solé D, Wandalsen GF, Camelo-Nunes IC, Naspitz CK. Prevalence of symptoms of asthma, rhinitis and atopic eczema among Brazilian children and adolescents identified by the International Study of Asthma and Allergies in Childhood (ISAAC) Phase 3. J pediatr (Rio J). 2006:82:341-6.

21. Boros CA, Kay D, Gold MS. Parent reported allergy and anaphylaxis in 4173 South Australian children. J Paediatr Child Health. 2000;36:36-40.

22. Tejedor-Alonso MA, Moro-Moro M, Múgica-García MV. Epidemiology of anaphylaxis: contributions from the last 10 years. J Investig Allergol Clin Immunol. 2015;25:163-75.

23. Alexandre-Silva GM, Brito-Souza PA, Oliveira ACS, Cerni FA, Zottich U, Pucca MB. The hygiene hypothesis at a glance: Early exposures, immune mechanism and novel therapies. Acta Trop. 2018;188:16-26. Não foram declarados conflitos de interesse associados à
publicação deste artigo.

Correspondência:

Cayo Fernando de-Araújo-Sousa

E-mail: cayo89@gmail.com 